\title{
Civilização ou barbárie
}

\section{Civilization or barbarism}

Lucia Regina Florentino Souto', Gustavo Souto Noronha², Ana Maria Costaㄹ, Telma Ruth Pereira4, José Carvalho de Noronha 5

DOI: 10.1590/0103-11042018S310

'Fundação Oswaldo Cruz (Fiocruz), Escola Nacional de Saúde Pública Sergio Arouca (Ensp), Departamento de Direitos Humanos, Saúde e Diversidade Cultural (DIHS) - Rio de Janeiro (RJ), Brasil. Orcid: https://orcid. org/0000-0003-22708424

luciafsouto@yahoo.com.br

2 Instituto Nacional de Colonização e Reforma Agrária (Incra) - Rio de Janeiro (RJ), Brasil. Orcid: https://orcid org/0000-0001-78606641

noronha.gustavo@gmail.com

${ }^{3}$ Escola Superior de Ciências da Saúde (ESCS)

- Brasília (DF), Brasil. Orcid: https://orcid. org/0000-0002-19313969

dotorana@gmail.com

4 Fundação Oswaldo Cruz (Fiocruz), Iniciativa Brasil Saúde Amanhã - Rio de Janeiro (RJ), Brasil. Orcid: https://orcid org/0000-0002-23565544

ruthtelma@gmail.com

5 Fundação Oswaldo Cruz (Fiocruz), Instituto de Comunicação e Informação Científica e Tecnológica em Saúde (ICICT) - Rio de Janeiro (RJ), Brasil.

noronhajc@gmail.com
RESUMO O artigo buscou entender os desafios para a construção de uma sociedade amparada em direitos sociais e de cidadania dentro da atual crise do capitalismo e do golpe de 2016. Contextualiza o atual cenário com o qual se defronta para, em seguida, discutir o conflito pela distribuição da riqueza. Posteriormente, traz a discussão do golpe e mostra as diversas tentativas de desconstrução da Constituição de 1988 que culminam na Emenda Constitucional 95. Nesse cenário, observa as perspectivas para o Sistema Único de Saúde (SUS) e conclama à retomada do espírito de 1988.

PALAVRAS-CHAVE Democracia. Direitos socioeconômicos. Capitalismo. Constituição e estatutos. Sistema Único de Saúde.

ABSTRACT The article seeks to understand the challenges for building a society based on social rights and citizenship within the current crisis of capitalism and the coup of 2016. It contextualises the current scenario we face and then discusses the conflict over the distribution of wealth. Next, it brings the discussion of the coup and shows the various attempts to deconstruct the 1988 Constitution which culminate in Constitutional Amendment 95. In that scenario, it observes the perspectives for the Unified Health System (SUS) and calls for a resumption of the spirit of 1988.

KEYWORDS Democracy. Socioeconomic rights. Capitalism. Constitution and bylaws. Unified Health System. 


\section{O panorama que nos defrontamos}

Oito bilionários possuem tanta riqueza quanto 3,6 bilhões de pessoas no planeta. O 1\% mais rico possui mais riqueza que os outros $99 \%$. Nos próximos 20 anos, 500 pessoas passarão mais de US\$ 2,1 trilhões para seus herdeiros, mais que o Produto Interno Bruto (PIB) da Índia com seus 1,2 bilhão de habitantes. Enquanto a renda dos 10\% mais pobres aumentou cerca de US\$ 65 entre 1988 e 2011, a do $1 \%$ mais rico cresceu cerca de US\$11.800, 182 vezes mais. Um diretor executivo de qualquer uma das 100 companhias com maior valor de mercado da Bolsa de Londres ganha o mesmo em um ano que 10 mil pessoas que trabalham em fábricas de vestuário em Bangladesh. Uma pesquisa recente realizada pelo economista Thomas Piketty ${ }^{1}$ nos Estados Unidos revela que, nos últimos 30 anos, a renda dos $50 \%$ mais pobres permaneceu inalterada em face de um aumento de $300 \%$ do $1 \%$ mais rico. O homem mais rico do Vietnã ganha mais em um dia do que a pessoa mais pobre ganha em dez anos ${ }^{2}$.

Piketty $^{1}$ demonstra, por meio de séries históricas seculares, que a desigualdade é inerente ao capitalismo. Com base em pressupostos plausíveis (que os ricos poupem o suficiente), a proporção entre riqueza herdada e renda (ou salários) continuará a crescer desde que a taxa média de retorno do capital exceda a taxa de crescimento da economia. Ele sustenta que esse é o padrão histórico, exceto durante a primeira metade do século XX, quando tivemos duas guerras mundiais e a revolução russa. Desse modo, vivemos em um modelo no qual a desigualdade crescerá a níveis nunca vividos. Os argumentos de Piketty', ainda que não se amparem em qualquer noção de luta de classes, reforçam o questionamento de que os modelos neoclássicos tendem a desconsiderar a alocação inicial dos fatores. Ou seja, se começamos desiguais, seremos cada vez mais desiguais.
Os atuais padrões de consumo da humanidade são insustentáveis. Anualmente, cerca de um terço de toda a produção mundial de alimentos (1,3 bilhão de toneladas com valor estimado de US\$ 1 trilhão) é desperdiçada. A degradação das terras, o declínio da fertilidade do solo, o uso insustentável da água, a pesca predatória e a degradação do ambiente marinho estão deteriorando a capacidade de atendimento da oferta de alimentos baseada no uso dos recursos naturais. Caso a população atual do mundo adotasse o padrão de consumo dos Estados Unidos da América (EUA), seriam necessárias hoje 4,1 Terras, o padrão da França, 2,5 Terras ${ }^{3}$. Menos de 3\% das reservas de água do mundo é potável, das quais $2,5 \%$ encontram-se congeladas nas regiões ártica, antártica e em geleiras, ainda assim a humanidade polui as fontes de recursos hídricos mais rapidamente que a capacidade natural de recuperação de rios e lagos. Ao mesmo tempo que o uso excessivo de água contribui para a escassez hídrica, um bilhão de pessoas não tem acesso à água potável. O consumo energético nos países da Organização para a Cooperação e Desenvolvimento econômico (OCDE) crescerá 35\% até 2020 e, apesar dos ganhos tecnológicos que tem promovido ganhos de eficiência, apenas um quinto da energia utilizada no mundo em 2013 foi de fontes renováveis ${ }^{4}$. Os Estados Unidos, com menos de $5 \%$ da população mundial, consome um quarto das reservas globais de combustíveis fósseis - $25 \%$ do carvão mineral, $26 \%$ do petróleo e $27 \%$ do gás natural ${ }^{5}$.

Dito isso, lembramos que o capital vai sempre criar necessidades irrelevantes. Devemos sempre lembrar que, na atual lógica, os produtos vão se tornando rapidamente obsoletos e que nos vemos obrigados a consumir para não ficarmos obsoletos. A cada ano, lança-se um novo aparelho de telefonia móvel; e, mesmo com o anterior funcionando perfeitamente, as pessoas sentem-se impelidas ao consumo, comprando os modelos de última geração. Em realidade, o 
consumo torna-se o principal culto da religião do capitalismo ${ }^{6}$.

É exatamente o modo de produção que permite o atual padrão de consumo que devasta nossas florestas e seca nossos rios, enfim, tem destruído o planeta e seus recursos naturais. Compromete assim o ciclo de chuvas, fertilidade do solo e, por consequência, a própria produção de alimentos para a população. As terras agriculturáveis vão se esgotando no atual modo de produzir e no seu avanço sobre as florestas nas fronteiras agrícolas, ainda que alguém concorde que possa aumentar a produção de alimentos no curto prazo, não se sustenta no longo prazo. O próprio padrão de produção agrícola hoje esgota o solo com suas monocultoras e envenena a terra, a água e os alimentos que consumimos. A vida da nossa espécie encontra-se ameaçada. Os impactos das atividades humanas influem no equilíbrio ecológico que permite a sobrevivência da espécie humana.

Friedrich Engels, citado por Rosa de Luxemburgo ${ }^{7}$, nos ensinou algo que, se podia não estar claro à época, hoje é límpido: "A sociedade burguesa se encontra diante de um dilema: ou avanço para o socialismo ou recaída na barbárie". Vivemos tempos difíceis, tempos de crise financeira, que, na verdade, vem se mostrando uma das mais profundas e resilientes crises econômicas do capitalismo, cujo futuro é imprevisível.

Não nos parece possível uma saída da crise sem a reversão do modo de ser da sociedade capitalista, o crescimento econômico como equação linear não resolve. Todavia a crise não é apenas econômica, é alimentar, energética e ecológica. É uma crise do atual sistema político e econômico.

Não por outra razão que o dilema socialismo ou barbárie, de fundamental importância para qualquer discussão política desde o século XIX, está mais atual que nunca. Ou melhor, barbárie se tivermos sorte, nos atualizou Mészaros ${ }^{8}$. O padrão de produção, distribuição, acumulação e consumo hoje existente nas nações europeias e americanas do norte não é reproduzível para o conjunto das pessoas do mundo.

Vivenciamos uma crise ecológica sem precedentes e, mais uma vez, precisamos voltar aos clássicos e atentar ao que Marx ${ }^{\text {9(132-133) já }}$ colocou em 'O Capital':

Com a preponderância sempre crescente da população urbana que amontoa em grandes centros, a produção capitalista acumula, por um lado, a força motriz histórica da sociedade, mas perturba, por outro lado, o metabolismo entre homem e terra, isto é, o retorno dos componentes da terra consumidos pelo homem, [...], à terra, [perturba] portanto a eterna condição natural da fertilidade do solo. [...] E cada progresso da agricultura capitalista não é só um progresso na arte de saquear o trabalhador, mas ao mesmo tempo na arte de saquear o solo, pois cada progresso no aumento da fertilidade por certo período é simultaneamente um progresso na ruína das fontes permanentes dessa fertilidade.

Para evitar a barbárie, que, aliás, já se abate em várias partes do mundo, há que se agregar a defesa do planeta como parte indissociável da luta pelo socialismo. As crises econômica, energética, alimentar e ecológica decorrem do insustentável padrão de consumo imposto pelo capitalismo. Desse modo, Mészaros ${ }^{8}$ nos aponta que a alternativa socialista não é só apenas possível, mas também necessária para a sobrevivência da Humanidade.

\section{A radicalização da tensão capitalismo e democracia: o conflito pela distribuição da riqueza}

A sociedade capitalista tal como conhecemos hoje foi moldada sob a ameaça do socialismo realmente existente. $\mathrm{O}$ estado de bem-estar social ou mesmo a macroeconomia keynesiana e suas preocupações com o 
emprego só foram possíveis e viabilizados em um contexto da ameaça do socialismo soviético, uma face humana do capitalismo fazia-se necessária para evitar o comunismo. A simples ideia de um capitalismo democrático só fazia sentido diante do 'sucesso' do socialismo real. O fim da utopia construída desde aquele fatídico outubro trouxe de volta a forma mais violenta do capitalismo de livre mercado, o neoliberalismo.

Entender como funcionou essa forma mais ou menos inclusiva do capitalismo requer compreender as nuances do debate econômico, que antes se encerrava na dicotomia capitalismo versus socialismo e hoje se concentra entre uma maior ou menor intervenção do Estado na economia. Subjacente a essa discussão está a controvérsia sobre a construção de um estado de bem-estar social com um sistema de seguridade social que proteja a população do desemprego e da perda da capacidade de trabalho (por doença ou velhice). As diversas sociedades se organizam em sistemas políticos que pendem entre uma ou outra opção, podendo variar conforme o tempo.

O grande dilema para o estabelecimento efetivo de uma sociedade na qual o Estado garanta o bem-estar social de seus cidadãos sempre foi sua capacidade de financiar o sistema de seguridade e garantir serviços públicos básicos como saúde e educação. A grande sacada da direita liberal foi associar toda a discussão sobre orçamento público que é complexa a uma linguagem que iguala a economia do setor público à economia doméstica, de forma que se repete à exaustão o mantra de que o 'o governo não pode gastar mais do que arrecada'.

Nesse sentido, é preciso reafirmar que não há objeção alguma à ampliação do gasto público para um país emissor de sua própria moeda, com oferta suficiente de trabalho e matérias-primas e sem restrições externas. Sempre que ocorrer deficit no setor público, haverá superavit no setor privado e, portanto, o superavit público significa um deficit das empresas e das famílias. Dito de outra forma, a responsabilidade fiscal, também conhecida como austeridade, é algo nocivo à sociedade. As decisões de políticas públicas deveriam se pautar, portanto, pela responsabilidade econômica e social sintetizada nas variáveis inflação e emprego, bem como na construção de um Estado de Bem-Estar Social.

$\mathrm{O}$ argumento dos economistas que defendem a austeridade parte da interpretação smithiana de moeda enquanto uma mercadoria. Entretanto, Innes ${ }^{10}$ demonstrou que a moeda é uma relação de crédito e débito. A aceitação de um débito de um determinado agente por outro é o ato que em si cria a moeda. De forma bastante simplificada, como há a obrigação do pagamento dos tributos, entende-se, portanto, que a moeda em última instância seria uma criatura do Estado"1" Sob esta ótica, ainda de maneira bastante abreviada, o dispêndio público seria financiado sempre pela emissão monetária, enquanto a tributação e o endividamento do estado seriam apenas formas de reduzir a quantidade de moeda em poder do público.

Desse entendimento, deriva-se a ideia das finanças funcionais, um contraponto à ideia das finanças saudáveis que tem embasado todo o pensamento de austeridade e coloca os governos reféns dos resultados fiscais ${ }^{\mathbf{1 2}}$. Nessa perspectiva, rejeita-se a ideia de equilibrar o orçamento governamental em um ano ou qualquer outro período arbitrário para que o gasto público seja orientado pelo nível do emprego e pela taxa de inflação.

Kalecki13 ressaltava, em 1942, na abertura de seu 'Aspectos políticos do pleno emprego', que uma maioria consolidada dos economistas já seria da opinião de que, mesmo em um sistema capitalista, o pleno emprego poderia ser assegurado por um programa de gastos do governo, desde que houvesse um plano adequado para empregar toda a força de trabalho existente, e desde que a oferta de matérias-primas estrangeiras necessárias pudesse ser obtida em troca de exportações. Kalecki ${ }^{13}$ continua correto.

No mesmo texto, entretanto, Kalecki ${ }^{13}$ colocava que apesar de a maioria dos 
economistas concordar que o pleno emprego poderia ser alcançado pelos gastos do governo, não teria sido este o caso, mesmo no passado recente (passado recente em relação ao seu texto). Kalecki13 classifica os opositores da doutrina do pleno emprego como proeminentes e autointitulados 'especialistas econômicos' estreitamente ligados à banca e à indústria. Fica evidente, portanto, que, pelo menos desde os anos 1940, as razões de natureza política prevalecem na defesa de políticas de austeridade pelo mundo. Kalecki ${ }^{13}$ nos apresenta três dessas razões.

Primeiro, em um sistema de livre mercado, o nível de emprego depende sobretudo da confiança dos agentes. Isso dá aos capitalistas, segundo Kalecki13, um poderoso controle indireto sobre a política governamental: tudo o que pode abalar o estado de confiança deve ser evitado porque isso causaria uma crise econômica.

A segunda razão das oposições políticas advém da direção do gasto público. Primeiro, se o investimento público ocorre em qualquer direção em que o capital possa competir com o Estado, ele não será bem-vindo, ou, na melhor das hipóteses, será aceito de forma precária. Um sistema público de saúde eficiente e funcional elimina, por exemplo, o mercado de planos de saúde, o mesmo se aplica à educação pública em contraponto ao ensino privado ou à existência de empresas estatais que concorrem (ou monopolizam) nos mais diversos mercados.

Ainda na direção do dispêndio público, mesmo os subsídios ao consumo de massa (transferências às famílias, subsídios a bens de primeira necessidade etc.) não são bem vistos. Mesmo não embarcando em qualquer tipo de empreendimento e ainda aumentando o lucro das empresas, Kalecki13 nos alerta que a oposição a esse tipo de gasto costuma ser mais violenta que ao investimento público, pois, neste caso, está em jogo um dos princípios morais basilares do sistema capitalista, 'você deve ganhar o seu pão com seu suor'.

Por fim, a terceira e última razão para os capitalistas se oporem a qualquer política de pleno emprego são as eventuais mudanças políticas e sociais dele decorrentes. O natural empoderamento da classe trabalhadora em um regime no qual a demissão não teria mais o seu caráter disciplinador. O poder de barganha e a consciência de classe do trabalhador aumentariam, seriam naturais o aumento das greves e do tensionamento político. Ainda que com maiores rendimentos, Kalecki13 nos coloca que:
a 'disciplina nas fábricas' e a 'estabilidade po-
lítica' são mais apreciadas do que os lucros pelos líderes empresariais. Seu instinto de classe lhes diz que um pleno emprego dura- douro é inaceitável a partir do seu ponto de vista, e que o desemprego é uma parte inte- grante do sistema capitalista 'normal'.

Em outras palavras, é preciso desemprego para colocar a classe trabalhadora no seu devido lugar.

Caso um governo que busque o pleno emprego se mantenha por um longo período, certamente haverá uma aliança entre a indústria e a banca para desmontar esse tipo de política. Kalecki13 profetiza que há de se encontrar mais de um economista para declarar que a situação era manifestamente frágil. Esse conjunto de forças necessariamente induziria uma guinada rumo a uma política ortodoxa para reduzir os deficit orçamentários. Somente na recessão subsequente os gastos governamentais voltariam a ser aceitos. Por fim, conclui seu texto dizendo que:

Se o capitalismo puder se ajustar ao pleno emprego, uma reforma fundamental terá sido incorporada nele. Caso contrário, se mostrará um sistema ultrapassado que deverá ser descartado ${ }^{13}$.

As digressões dele foram feitas em uma palestra proferida à Sociedade Marshall, em Cambridge, na primavera de $1942^{13}$. A história nos mostrou que o capitalismo não apenas não incorporou o pleno emprego 
como direcionador das políticas econômicas como também vem se constituindo em um sistema devastador para todo o planeta.

Na verdade, Polanyi ${ }^{14(232)}$ já nos alertava que "a maior parte da confusão existente na teoria monetária se devia à separação entre política e economia”. Os liberais normalmente sempre argumentam que uma espécie de conspiração coletivista impede os benefícios plenos do liberalismo, pois continuamente mina os esforços para a aplicação da agenda liberal que salvaria a economia; é interessante notar que eles constantemente alegam que as medidas adotadas são insuficientes e pedem mais e mais liberalismo. Felizmente essa ideia já foi desconstruída por Polanyi ${ }^{14}$. No entanto, Braudel15(579) nos mostra de maneira mais enfática as relações de interdependência entre o Estado e o Capital:

Os homens de negócios gostam de dizer que a política ocupa atualmente o principal papel, que o poder do Estado é tal que nem o banco, nem o grande capital industrial contam com relação a ele. E, claro, não faltam analistas sérios que falam do Estado mastodonte, do Estado que tudo esmaga e retira a iniciativa do setor privado, da liberdade benéfica do 'inovador'. Dever-se-ia obrigar esse mastodonte a voltar ao seu antro. Mas também lemos o contrário, ou seja, que a economia e o capital invadem tudo, esmagam a liberdade dos indivíduos. Na realidade, não nos deixemos enganar, Estado e Capital, ou pelo menos um certo capital, o das grandes firmas e dos monopólios, formam um bom casal, e este último, sob nossos olhos, sai-se muito bem. [...] graças às suas boas relações, à sua simbiose com - Estado, distribuidor de vantagens fiscais (para ativar o sacrossanto investimento), de encomendas suntuosas, de medidas que the abrem melhor os mercados externos, é que o 'capitalismo monopolista' [...] prospera. [...] [O] entendimento entre o Capital e o Estado não é de hoje. Atravessa os séculos da modernidade, a ponto de, cada vez que o Estado vacila [...] vermos o capitalismo acusar o golpe.
Se o momento atual não possui o padrão ouro que quando se dissolveu "a própria civilização foi engolfada”14(256-257), a mesma incompatibilidade entre o capitalismo e a democracia está presente. Polanyi ${ }^{14(264)}$ foi categórico ao afirmar que "não houve um único militante liberal que deixasse de expressar a sua convicção de que a democracia popular era um perigo para o capitalismo". Isso fica claro quando ele coloca:

A separação de poderes, que Montesquieu (1748) havia inventado nesse intervalo, era usada agora para isolar o povo do poder sobre a sua própria vida econômica. A constituição norte-americana, modelada num ambiente de fazendeiros e artífices por uma liderança já precavida pelo cenário industrial inglês, isolou completamente a esfera econômica da jurisdição da constituição, colocando a propriedade privada sob a mais alta proteção concebível, e criou a única sociedade de mercado legalmente constituída no mundo. Apesar do sufrágio universal, os eleitores norte-americanos não tinham poder contra os proprietários ${ }^{14(264)}$.

No Brasil atual, a Lei de Responsabilidade Fiscal e a recente Emenda Constitucional - EC no 95 são exemplos concretos do isolamento da esfera econômica de qualquer influência do poder político.

$O$ processo de transição do capitalismo industrial para o capitalismo financeiro nos últimos 30 anos radicaliza a tensão capitalismo e democracia, constituindo-se em um dos desafios cruciais à difícil democracia diante do deficit democrático produzido pelo processo global de desorganização do Estado democráticos, as democracias sociais, do pós-guerra. Os neoliberais pretendem desorganizar o Estado democrático por meio da inculcação na opinião pública da suposta necessidade de várias transições, como menciona Santos ${ }^{16}$.

Streeck ${ }^{17}$ se refere a esse processo de transição do capitalismo industrial para o financeiro nos últimos 30 anos como a 
desdemocratização do capitalismo - ou o que designa como hayekização do capitalismo. Hayek, citado por Streeck 17, em 1939, escreveu artigo precursor do que viria a ser a configuração da União Europeia, propondo uma instância técnica, restrita à especialistas, a partir de argumentos como: intervenções políticas no mercado seriam intoleráveis e prejudiciais; e a necessidade de restringir o alcance e a profundidade da política econômica de cada Estado-membro, como, por exemplo, ter política monetária própria. Essa configuração 'política' cria a farsa de 'especialistas', não políticos, disporem da vida de milhões de pessoas em nome da técnica, da economia.

$\mathrm{O}$ custo tem se mostrado elevado. $\mathrm{O}$ estudo de Piketty ${ }^{\mathbf{1}}$ sobre as dinâmicas que movimentam a acumulação e a distribuição do capital constata que a taxa de rendimento do capital supera o crescimento econômico, o que se reflete em uma concentração cada vez maior de riqueza e aumento das desigualdades. Um ciclo vicioso de desigualdade que ameaça os valores democráticos.

Streeck $^{\mathbf{1 8}}$ afirma que estaríamos vivendo a agonia do capitalismo. Os sintomas seriam cinco doenças sistêmicas do capitalismo: estagnação, redistribuição oligárquica, pilhagem do setor público, corrupção e anarquia global.

A redistribuição oligárquica implica o descolamento dos capitalistas da economia. A pilhagem do setor público se dá pela apropriação privada do Estado: no mesmo compasso em que os ganhos de renda se concentram no $1 \%$ mais rico, o setor público das economias capitalistas encolhe de forma dramática. A austeridade imposta à sociedade é mais uma expressão do deslocamento da economia dos oligarcas da economia das pessoas comuns.

O domínio do setor financeiro na economia e as finanças como indústria colocam a corrupção em um patamar ilimitado. A crise de 2008 transpareceu apenas a ponta de um iceberg, mas que expôs a extravagância da corrupção como as agências de classificação de risco remuneradas por emissores de papéis podres, dando-lhes melhores notas, a farra dos paraísos fiscais e diversas e sofisticadas formas de manipulação do mercado financeiro ${ }^{18}$.

A anarquia global, para Streeck ${ }^{\mathbf{1 8}}$, apareceria em um quadro de instabilidade crescente diante da dificuldade de os EUA continuar a exercer o papel de centro monetário digno de confiança, como a Grã-Bretanha, na década de 20, e os Estados Unidos, entre 1945-1970. Todavia, da mesma forma como descrito por Tavares ${ }^{\mathbf{1 9}}$, para o final dos anos 1970 e início da década de 1980, os EUA parecem voltar à estratégia da retomada da sua hegemonia por meio do dólar forte, como agora, sob a égide de Donald Trump.

As políticas de austeridade, como comenta Santos ${ }^{16}$, visam esvaziar a democracia representativa das políticas de inclusão social alimentando a tensão democracia e capitalismo. Para ele, as resistências podem ser construídas a partir das causas ou a partir das consequências dessas políticas. Quando construída a partir das causas, a captura do Estado por forças antidemocráticas com sua enorme concentração de renda e restrição de direitos, a resistência se assenta na ampliação de direitos e na convicção de que são políticas arbitrárias e injustas, que optam por salvar bancos e impor pobreza às famílias. Quando a resistência é construída a partir das consequências das políticas de austeridade, apoia-se na convicção de que estas são resultados dos excessos de bem-estar, de direitos e proteção social ${ }^{16}$.

Aqui é importante resgatar a ideia de que, após o colapso, as ideias neoliberais se tornaram hegemônicas, todavia, após a crise de 2008, concepções do século XIX parecem retornar, pois:

tudo que era tido como sólido e estável se desmancha no ar, tudo quanto era sagrado é profanado, e os homens são obrigados, enfim, a encarar de frente, sem ilusões, suas condições de existência e sua relação recíproca20(55). 
Os eventos de 2008 desmancharam no ar as sólidas análises das agências de classificação de risco e desmistificaram a utopia neoliberal.

Isso se desenrola em um cenário no qual o sistema internacional parece cada vez mais caótico. Há um novo arranjo global, como demonstrou Fiori21, em que nos deparamos com uma mudança no sistema internacional em que a ordem internacional fundada numa ética de referência comum global, desapareceu. Um sistema no qual há um país (China) recém-incorporado à ordem internacional capitalista com um quinto da população do mundo, cuja civilização nada tem a ver com a civilização cristã ocidental.

Este sistema, neste momento, está girando com uma regra só, [...] acabou-se a possibilidade de arbitragem ética internacional, não tem mais árbitro e, portanto, o que vale aqui é o interesse americano, ali vale o interesse russo e lá vale o interesse chinês. E este é o famoso sistema de Westfália, criado em 1648 , que virou em guerra permanente até o século XIX, quando finalmente em Viena se estabelecia uma regra básica de convivência entre as potências. Porque no sistema de Westfália, que estamos neste momento, só tem uma regra: é cada um por si e, na divergência, a guerra21.

\section{Um golpe nos direitos do povo}

Fingindo-se indignada com a corrupção, a elite brasileira patrocinou a destituição da presidenta Dilma Rousseff no processo do golpe de 2016. O tema da corrupção - como mostram vários autores, Souza ${ }^{22}$, Santos ${ }^{23}$ - sempre foi uma retórica utilizada para ocultar a reação das elites brasileiras escravocratas e subalternas diante das derrotas eleitorais para projetos de cunho democrático popular e afirmação de políticas de cunho social, de soberania. A mesma retórica foi utilizada contra Juscelino, sendo até aventada, à época, por Carlos Lacerda a ilegalidade de sua vitória por ter recebido votos de comunistas, cujo Partido Comunista Brasileiro (PCB) estava na ilegalidade. As denúncias de corrupção são novamente utilizadas como parte das justificativas, com a bandeira do anticomunismo, para a derrubada de João Goulart. O ponto comum entre os golpistas é a rejeição a um progresso econômico com políticas distributivas e direitos de cidadania.

Souza 22(112) comenta que em toda a história republicana "o mote da corrupção é sempre usado como arma letal para o inimigo de classe da elite e seus aliados". Como ressalta, isso sempre ocorre toda vez que se pratica políticas de inclusão dos setores marginalizados, com menor participação no orçamento dos endinheirados e aumento relativo do salário dos trabalhadores, ou quando o Estado conduz políticas de desenvolvimento de longo prazo.

A ideia é que a riqueza do país já tem dono, ou seja, ela é privada e deve ser privatizada. São esses os dois crimes que estão, verdadeiramente por trás de toda manipulação da corrupção brasileira22(112).

O golpe de 2016 expressou a reiteração do pacto das elites do dinheiro e do conhecimento vigente desde o fim da escravidão e do nascimento do capitalismo moderno entre nós ${ }^{22}$. Souza ${ }^{24}$ coloca que 'no Brasil atual prospera uma sociedade sem culpa e sem remorso, que humilha e mata os pobres'. As interpretações hegemônicas ancoradas no patrimonialismo e no populismo atuam na reprodução e eternização de privilégios. A tese do patrimonialismo oculta a captura do Estado pelo mercado via sua demonização e exaltação do mercado virtuoso. O tema do populismo desqualifica qualquer coisa oriunda das camadas populares, incapazes de reflexão e sempre sujeitas à manipulação por líderes populistas.

Além da diferença essencial entre os golpes de 1964 e 2016, relativa à técnica adotada, o golpe parlamentar, Santos ${ }^{23}$ 
considera que há algo mais em 2016 do que o medo anticomunista de 1964, bem como algo menos. O pavor irracional ao comunismo é o ausente atual porque o fantasma do anticomunismo já não mobiliza como antes, as menções à Cuba não se comparam com a proporção que adquiriu a Marcha da Família com Deus pela Liberdade em 1964. O que há a mais é o repúdio visceral às políticas distributivas de enfrentamento das desigualdades.

Santos $^{23}$ descreve que o golpe parlamentar em sociedades de democracia representativa de massas significa o sequestro do poder constituinte do povo. A Constituição passa a ser dogmaticamente reinterpretada pelo governo golpista, sobre o que é constitucional e o que é crime contra a Constituição. Sem o acordo tácito entre considerável maioria do judiciário e do Legislativo, não há golpe parlamentar. Os golpes parlamentares constituem um fenômeno novo na história das tensões entre capitalismo e democracia.

Nas palavras de Santos ${ }^{23(8)}$ :

A trapaça nacional compõe capítulo suburbano de eminente processo de longa duração em que as utopias de sociedades fundadas na solidariedade foram dizimadas pela horda dos acumuladores e concentradores de lucros. Esta história tem um sentido disputado por filósofos e analista sociais.

Para Souza ${ }^{22}$, a associação de uma justiça escancaradamente seletiva, um parlamento comprado, uma mídia partidarizada, uma base social radicalizada criou o clima insurrecional que possibilitou o golpe. Em sua análise da dinâmica social do golpe sobre as jornadas de junho de 2013, comenta o protagonismo da classe média conservadora como base social do golpe, uma fração privilegiada, branca e bem-vestida, que passava a impressão de defender o 'interesse nacional': uma mudança para o melhor para todos.

O componente moral também foi decisivo e atuou em dois sentidos. O primeiro foi incutir nessa fração de classe o sentimento de protagonismo no movimento, ainda que, na verdade, fosse um mero instrumento de manipulação do consórcio golpista elites/mídia. Esse sentimento foi construído com maestria sob a batuta do Jornal Nacional. O segundo dado decisivo da construção moral desse grupo foi a substituição, construída pouco a pouco, das bandeiras por melhores serviços públicos pela bandeira - a essa altura ainda abstrata - do combate à corrupção e a Proposta de Emenda Constitucional - PEC $37^{22}$.

A integração dessa fração conservadora à dinâmica do golpe foi decisiva. A primeira tentativa de golpe pelo consórcio golpista, mídia, congresso comprado e justiça justiceira estava presente no processo do chamado 'mensalão' em 2005. O ensaio geral do mensalão fracassou apesar da feroz campanha midiática; Lula foi reeleito pela adesão popular às políticas de inclusão social, pois, como comenta Souza, para as camadas populares, a corrupção é um dado universal da 'política dos ricos'22.

\section{As resistências contra a Constituição Cidadã}

A Constituição de 1988 inaugurou etapa inédita de construção da cidadania, um sistema de proteção social inspirado em valores de Estado de Bem-Estar Social que sofrem longo processo de reação a essas conquistas.

Logo no seu alvorecer, o então presidente José Sarney afirmou que o País ficaria 'ingovernável' se aprovado o capítulo da ordem social. Em 1990, após a eleição de Fernando Collor, chegou ao Brasil o grande consenso favorável às políticas de ajuste e às contrarreformas do Consenso de Washington, uma agenda que foi parcialmente interrompida com impeachment. Itamar Franco, apesar da estabilização da economia, trouxe com ele o Fundo Social de Emergência (Posteriormente, Desvinculação de Receitas da União - DRU) que permitiu a desvinculação de $20 \%$ das fontes financiamento constitucionais. 
Fernando Henrique Cardoso, em seu último discurso no Senado antes de assumir a presidência, anunciou 'o fim da era Vargas'. Introduziram-se aí as políticas de austeridade com a institucionalização do superavit primário e com a limitação da política fiscal do governo federal com a Lei de Responsabilidade Fiscal. Foi feita uma reforma da previdência com a incorporação de critérios financeiros e atuariais nos regimes previdenciários, além do fim da aposentadoria por tempo de serviço, sendo substituída pelo tempo de contribuição. A política monetária foi recorrentemente recessiva, inclusive com a revogação do limite constitucional de $12 \%$ para a taxa de juros. Além disso, foram feitas diversas privatizações, sempre a partir de uma estratégia de desenvolvimento subalterna à potência hegemônica, os EUA

No início da década de 2000, o sistema de saúde brasileiro encontrava-se fraturado em dois. De um lado, um sistema para ricos e remediados, com redução ou quebra de cobertura nas doenças crônicas e na velhice, que obtém algum grau de regulação com a aprovação da Lei ${ }^{\circ}$ 9.656/1998. De outro, o Sistema Único de Saúde (SUS), de caráter público e nominalmente universal, utilizado por $75 \%$ da população, ainda fragmentado, múltiplo, descentralizado, com escassa coordenação e articulação, sub-remunerado, com ênfase nas prestações médico-assistenciais sem definição de prioridades e orientado pela oferta de serviços.

A complexa explicação da privatização setorial decorre principalmente de políticas econômicas articuladas com concessão de benefícios e tributos, que permitiu ganhar a adesão de empregadores e empregados e, de forma perversa, estabeleceu uma conjugação de bases do financiamento e incentivos oriundos do fundo público, modelando uma assistência fragmentada e estratificada na sociedade e no interior das próprias empresas ${ }^{25}$.

A despeito de a saúde integrar a seguridade social e assumir a condição de direito social universal, o Brasil destoa dos países que dispõem de sistemas universais na composição entre arranjos públicos e privados de financiamento e provisão de serviços. Os gastos per capita mostram a distância entre $o$ tamanho dos gastos públicos no Brasil e nos países desenvolvidos, medidos em paridade de poder de compra: 611 para o Brasil, 3.288 para o Reino Unido, 4.408, Suécia, 3.574, França, e 4.696 para os EUA26,27.

\section{A EC 95 e a devastação anunciada}

A Constituição de 1988 fixou 25\% da receita de contribuições da Seguridade Social para o financiamento federal das ações e serviços de saúde. A DRU, vigente desde o Fundo Social de Emergência do governo Itamar Franco, impediu que prosperasse a vinculação; e, em 2000, a EC n ${ }^{\circ} 29$ vinculou receitas de estados e municípios em $12 \%$ e $15 \%$, respectivamente (regulamentada pela Lei Complementar $\left.\mathrm{n}^{\mathrm{o}} 141 / 2012\right)^{\mathbf{2 8}}$, e rompeu, para a União, com a dedicação das contribuições sociais à Saúde e associou seu crescimento a variações nominais do PIB.

Os anos 1990 trouxeram o engessamento do executivo federal com alguns pontos da Lei de Responsabilidade Fiscal e da DRU, entretanto, a aprovação da EC no 95/2016 estabeleceu um padrão ainda mais radical de contenção do Estado. O novo regime fiscal só foi feito na forma de uma emenda constitucional porque os recursos de saúde e educação possuíam regras constitucionais que protegiam seus gastos ${ }^{29}$.

O que está em questão é a visão neoliberal de uma recorrente crise fiscal fruto do aumento de gastos sociais da Constituição Federal de 1988 que não caberia no orçamento. A ideologia é a mesma de Margaret Thatcher e Ronald Reagan com o pensamento único na economia, pois 'não há alternativa' (Tina, there is no alternative).

O documento 'Austeridade e retrocesso', 
elaborado por um conjunto extenso de pesquisadores, detalha os efeitos da $\mathrm{EC} \mathrm{n}{ }^{\circ} 95$, o gráfico 1, apresentado no documento, estima as despesas primárias do governo federal com emenda do teto dos gastos em percentual do PIB. A simulação supõe uma taxa de crescimento de $1,7 \%$ para 2018 e de $2,5 \%$ para os outros anos.

Gráfico 1. Simulação das despesas primárias do governo federal com a EC 95 - em \% do PIB - 2017-2036

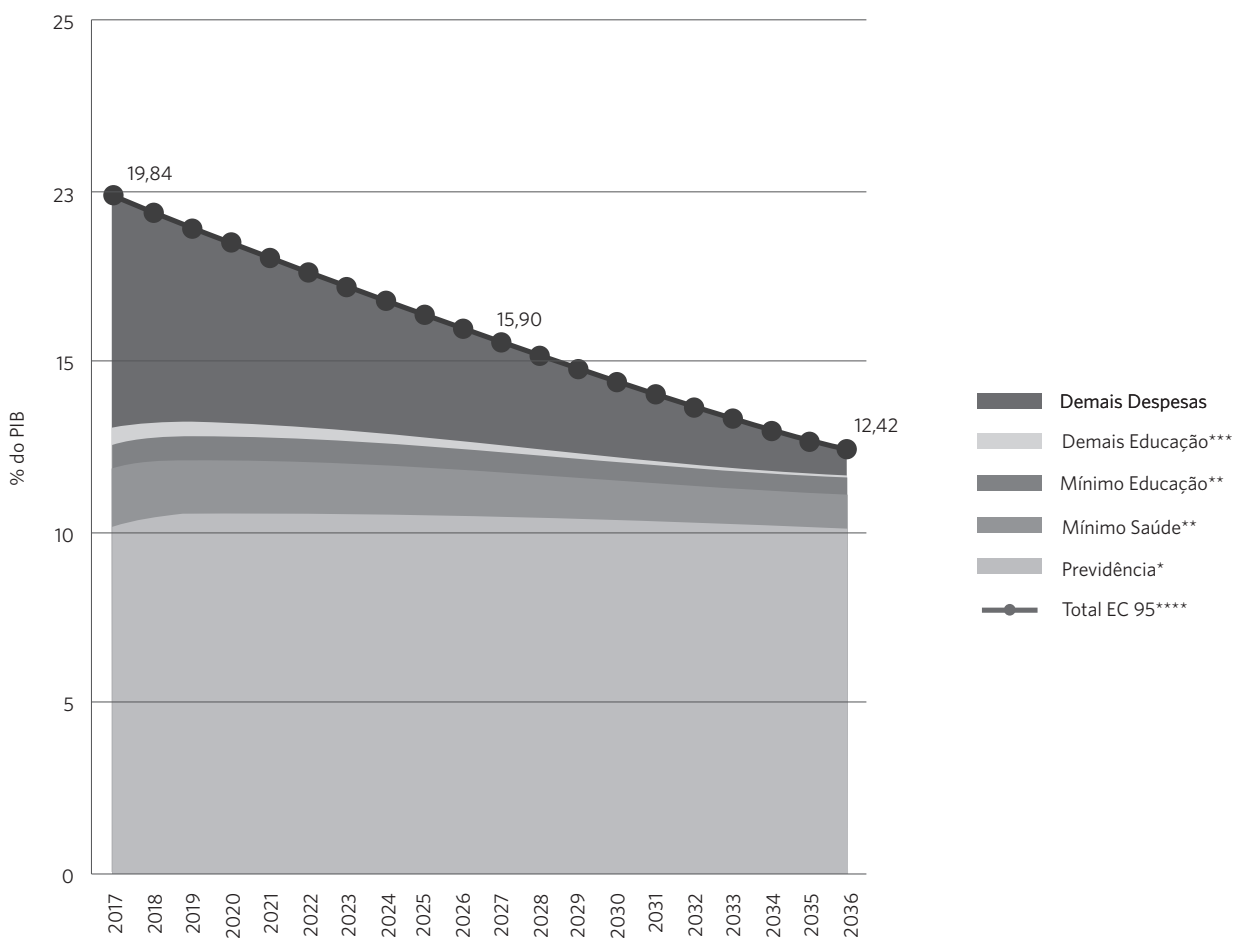

Fonte: Dweck, Oliveir, Rossi30

* Para os gastos com a previdência, assumiu-se que uma reforma manterá o RGPS com o mesmo percentual do PIB a partir de 2020.

**Dados do Relatório Resumido de Execução Orçamentária de dezembro de 2017, Mínimo Educação é 18\% da Receita Líquida de impostos, Mínimo da Saúde, 15\% da Receita Corrente Líquida.

*** são os demais pagamentos da função educação que contam para o Teto de Gastos, mas não estão sujeitos ao mínimo, de acordo com relatório do Tesouro Nacional.

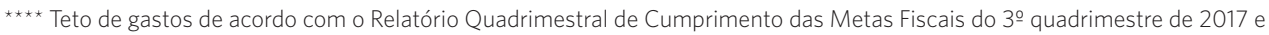
considerando a simulação acima referida.

Uma vez que as civilizações humanas do século XXI parecem achar reprováveis estratégias de solução final, e o gráfico já incorpora uma reforma radical da previdência, ou teremos um desmonte absoluto do Estado, ou uma privatização completa da previdência, de forma que o capital possa se apropriar de toda a área verde. Propostas de capitalização da previdência nos moldes feitos pela ditadura de Pinochet no Chile serão cada vez mais frequentes.

Como já dissemos, não há nenhum óbice que obrigue um país como o Brasil a autoimpor um teto ao gasto público. Assim, os gastos em saúde, previdência ou qualquer outro gasto do governo deveriam ser orientados pelos seus 
impactos econômicos e sociais. Do ponto de vista econômico, os gastos em saúde e educação possuem um alto efeito multiplicador ${ }^{31}$.

Entretanto, Kalecki ${ }^{13}$ nos apresentou as razões de natureza política que prevalecem na defesa de políticas de fiscais restritivas. Desse modo, um SUS estruturado, funcional e sem subfinanciamento cria muitas dificuldades, quando não inviabiliza, à atuação do capital tanto no mercado de planos de saúde quanto no provimento de serviços privados de saúde. Corte de gastos públicos, portanto, não tem relação com modernizar o Estado e torná-lo eficiente.

Dessa forma, as políticas de austeridade não têm a ver com qualquer tipo de restrição orçamentária para os gastos públicos, mas com as razões políticas que se manifestam nos diversos diplomas legais que impõem a doutrina das finanças saudáveis. $\mathrm{O}$ que se afirma aqui é que não se deve olhar os gastos sociais (saúde, previdência ou educação, por exemplo) sob a ótica de um resultado fiscal arbitrário, de um ano ou qualquer outro período que se queira, mas que se faça uma análise dos seus resultados econômicos e sociais.

\section{Ninguém quer a morte, logo a velhice chegará}

Desde seus primórdios, a humanidade busca a imortalidade. As religiões do passado e do presente (quiçá do futuro) manifestam a perplexidade com a finitude da vida humana e propõem soluções diversas para o que acontece após a morte. Magias, rituais e milagres se ocuparam, se ocupam e certamente se ocuparão dos modos de prolongar a vida na Terra.

Até as ciências baseadas na razão tratam do pós-vida. O filósofo britânico Gray ${ }^{32}$ publicou um livro intitulado 'A Comissão da Imortalização', que tem como subtítulo 'a ciência e a estranha busca de trapacear a morte', em que visita essa tentativa com humor, concisão e abrangência. A imortalidade aqui na própria Terra foi objeto da ciência, onde o alvorecer da química científica confluiu com a busca da pedra filosofal e do elixir da longa vida. A medicina, desde seu nascedouro, se não buscava a imortalidade, sempre tratou de adiar a visita da morte. Ocorre que ela sempre retornava.

Não bastasse o retorno da morte, sua ausência acarretaria problemas dramáticos, retratados na literatura pelo prêmio Nobel em literatura José Saramago em 'As intermitências da morte'. O livro conta o que acontece quando, em um país qualquer, as pessoas simplesmente param de morrer. Outro escritor português, Tavares ${ }^{33}$, publicou 'Uma viagem à Índia', à moda de uma epopeia lírica contemporânea, em que uma de suas estrofes entoa:

As várias gerações são egoístas, sem dúvida. Porque se os dias emperrassem numa geração específica - como roldana sem óleo que não avança -, estaríamos diante de uma magnífica raça eterna. O que muito faria contentes uns e incomodaria outros: aqueles que ainda não nasceram.

A duração da vida tem um limite? Vários estudiosos se dedicaram a analisar a evolução da duração da vida ao longo do tempo. Embora de maneira desigual, a esperança de vida ao nascer tem aumentado, fundamentalmente graças à redução da mortalidade na infância. Robine ${ }^{34}$ identificou uma idade modal de morte com relativa estabilidade que passa a ser detectável na Suécia aos fins do século XVIII, e na Suíça no século XIX, e se situa em torno dos 75 anos. O Japão, para os anos 1950, evidenciaria o que seria o fim da transição epidemiológica, situando a idade modal em torno dos 80 anos, bastante próxima da atual em todos os países do mundo desenvolvido.

Fries ${ }^{35}$ introduziu a ideia da 'Compressão da Morbidade', sugerindo que o aumento da esperança de vida se faria acompanhar de um encurtamento da extensão da vida com morbidade. As mesmas forças que resultaram na diminuição da mortalidade 
estariam associadas a uma menor incidência de doenças crônicas e a um aumento da idade de início dessas doenças. Entretanto, inúmeros estudos, desde meados dos anos 1970, têm demonstrado que isso não ocorre. Uma pessoa que morre aos 65 anos, por infarto agudo do miocárdio, por exemplo, consome bem menos serviços e produtos de saúde do que se sobreviver ao infarto e vier a falecer de câncer aos 90 anos. A redução da mortalidade não se acompanha necessariamente de uma redução da incidência, e aumenta o número de sobreviventes portadores de problemas de saúde que estarão sujeitos à ocorrência de problemas de saúde adicionais. A busca incessante por tecnologias de prolongamento exaustivo de nossas vidas fará sentido? Como trazer aos dias de hoje aqueles que, como na África subsaariana, mal chegam aos 52 anos? $\mathrm{E}$ os bolsões de miseráveis que ainda vivem entre nós e em vários países de renda média?

Trinta anos após a promulgação da Constituição, o Brasil mudou de maneira significativa seu perfil demográfico e epidemiológico. Registrou tendências que, grosso modo, não deverão sofrer grandes transformações nos 30 anos subsequentes, representadas na figura 1 . Segundo as projeções do Instituto Brasileiro de Geografia e Estatística $^{36}$ (IBGE), a população de maiores de 65 anos triplicou de 1988 a 2018, atingindo a cifra de 18,3 milhões, e chegará, em 2048, a 49 milhões de brasileiros, dos quais 14 milhões com mais de 80 anos.

Figura 1. Composição absoluta da população, por idade e sexo - Brasil - 1990, 2020, 2050

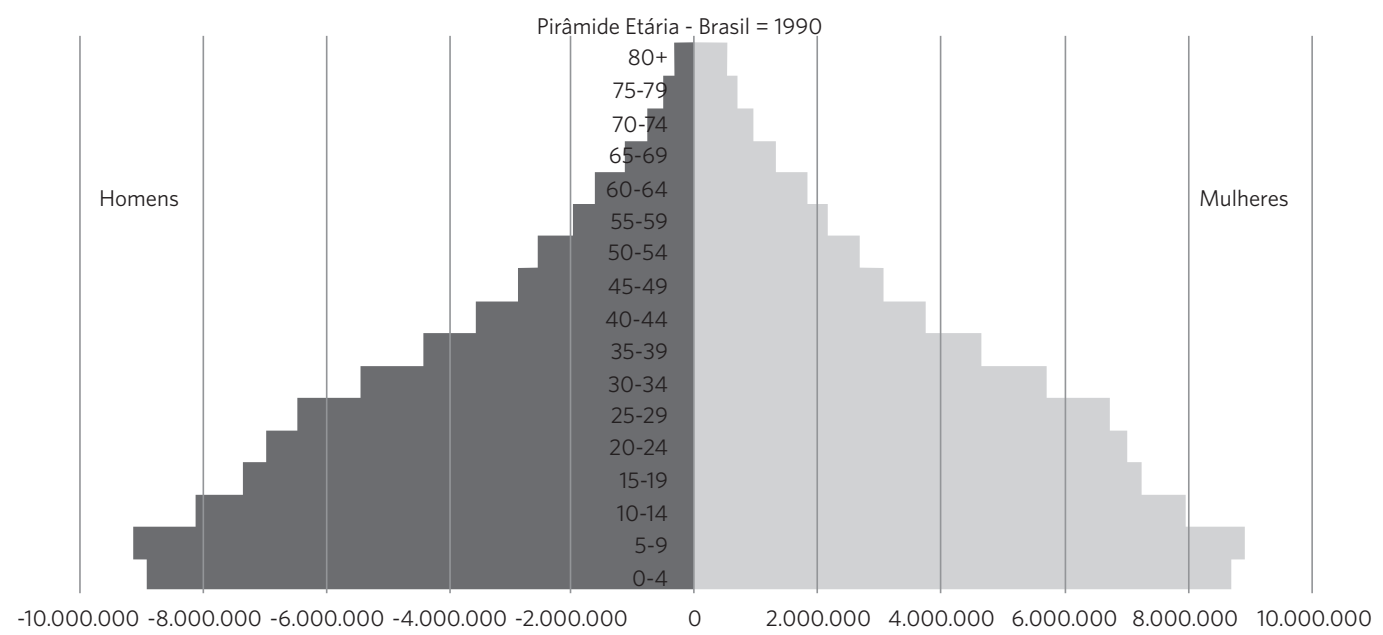


Figura 1. (cont.)
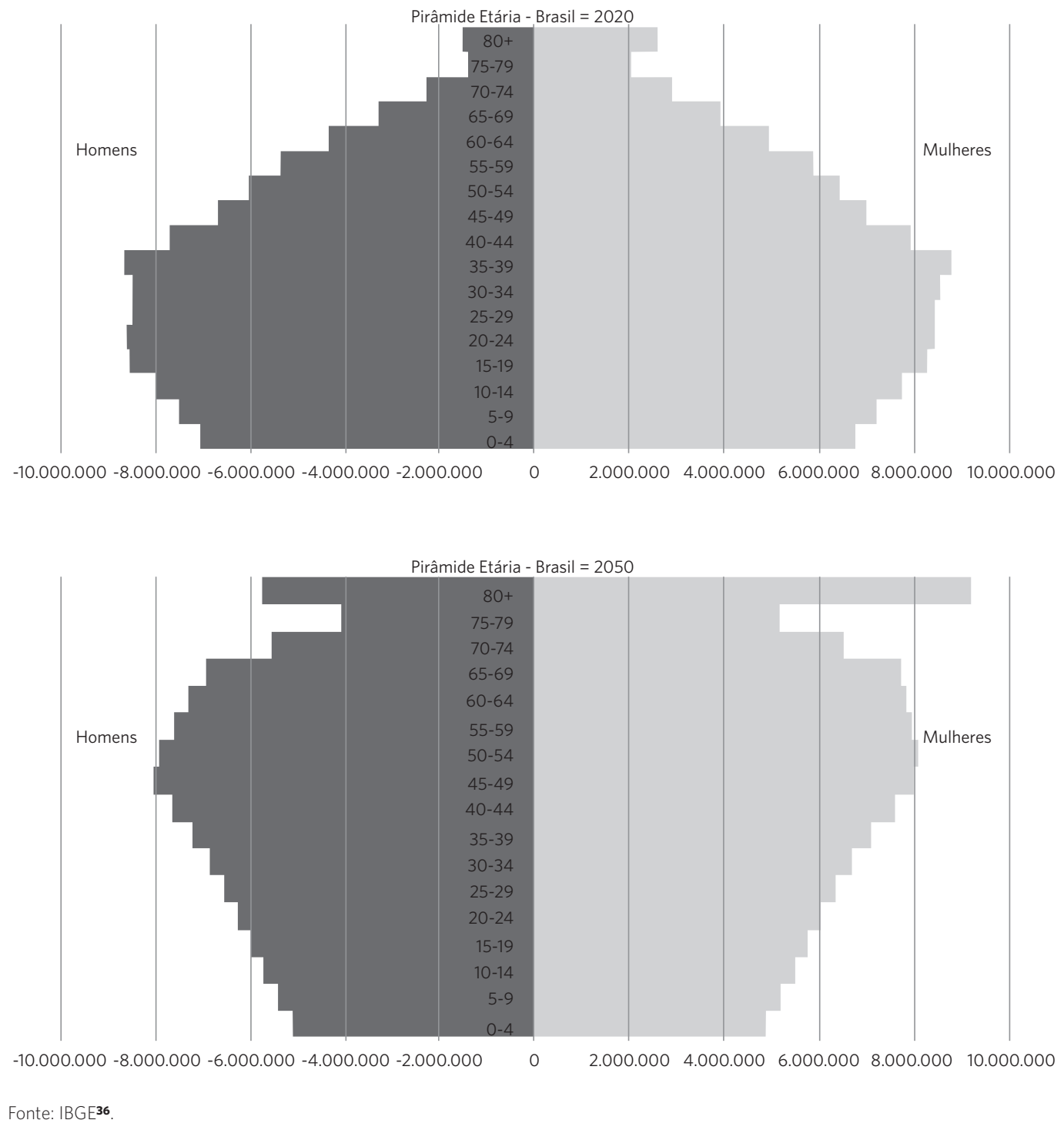

É um desafio quase impossível pensar um sistema de saúde equitativo para o quinto país em extensão territorial do mundo, maior que a União Europeia, com 27 unidades federadas e mais de 5 mil municípios de dimensões territoriais e populacionais, biomas e uso do solo, condições sociais e econômicas bastantes diversas.

O corte de gastos no setor público, acentuado pela revisão, no final de 2017, dos mecanismos das transferências do governo federal para municípios adotada pelo Ministério da Saúde, reduziu suas condicionalidades programáticas e agravou a fragmentação do sistema público e, indiretamente, como ocorrera na década de $1990^{37}$, estimulou os arranjos privados. A receita bruta das operadoras de planos de saúde, em 2016, foi aproximadamente 1,5 vez o orçamento do Ministério da Saúde. Ademais, se por um lado os gastos somados dos três níveis de governo no SUS cresceram $0,5 \%$ em termos reais entre $2012 \mathrm{e}$ 2016, por outro, os planos e seguros de saúde viram a receita bruta subir $27,0 \%$ no mesmo 
período. Em 2016, a média de gasto por pessoa dos planos foi 2,55 vezes mais que o SUS, o gasto per capita dos 6,5 milhões de brasileiros cobertos pelas seguradoras $(3,5 \%$ da população) foi 4 vezes maior (cálculos a partir de dados do Sistema Integrado de Planejamento e Orçamento - Siop ${ }^{\mathbf{3 8}}$ e da Agência Nacional de Saúde Suplementar - ANS ${ }^{39}$ ).

Outro ponto de destaque são os recursos que deixam de ir para o SUS por conta deduções no imposto de renda de pessoas físicas, tanto em planos individuais como em coparticipações em planos coletivos ${ }^{\mathbf{4 0}}$. Estima-se o total de gastos tributários da União para a função saúde para 2018 em cerca de R $\$ 39$ bilhões, dos quais $\mathrm{R} \$ 18$ bilhões referiam-se a despesas com assistência à saúde ${ }^{41}$.

Dessa restrição fiscal, configura-se uma tendência à intensificação da concorrência entre os entes federados e, no interior destes, entre os prestadores. Também caminha para inviabilizar a organização em rede dos serviços com fragmentação e segmentação dos cuidados. Reduz-se ainda os investimentos em novas capacidade e cai a qualidade e a segurança dos serviços. A iniciativa privada acaba por produzir novos arranjos assistenciais, como as clínicas de vizinhança e clínicas populares. Também ocorre o desenvolvimento e fortalecimento de novas modalidades de pré-pagamento: planos populares, Vida Gerador de Benefícios Livres (VGBL), Saúde e franquias. Isso naturalmente resultará em um aumento da desigualdade territorial por riqueza e da estratificação do atendimento, além da concentração dos investimentos e inovações no setor privado de ponta.

As medidas compensatórias adotadas pelo governo, entre 2000 e 2015, permitiram a retirada de 28 milhões de pessoas da pobreza, enquanto a concentração de renda no $1 \%$ dos brasileiros no topo aumentava. Os seis brasileiros mais ricos do país são tão ricos que os $50 \%$ cento mais pobres. A tributação e o gasto público não têm reduzido as desigualdades históricas no Brasil ${ }^{42}$. Sem a reversão da $\mathrm{EC} n^{\circ} 95$, parece se confirmar o Brasil dos $20 \%$ descrito por Souza (2016). Ou ainda mais grave, um país que se supõe dos $20 \%$, mas que, em realidade, pertence ao seu $0,1 \%$ sempre comprometido a um projeto de país ancorado em um suposto equilíbrio fiscal, nos paradigmas da economia ortodoxa e na inserção subalterna na divisão internacional do trabalho.

Na sua crônica 'A evolução das espécies por seleção artificial', Diegues ${ }^{43}$ nos apresenta o Homo ricus, desenvolvido a partir de uma parcela da população que tem acesso a serviços avançadíssimos de terapia genética na fronteira tecnológica e acaba dissociada dos demais Homo sapiens. O uso do planeta pelos mais ricos e a não construção de um sistema público universal de saúde que forneça a toda a população os produtos e serviços de saúde mais avançados certamente transformarão a divisão de classes na divisão de espécies sugerida por Diegues ${ }^{43}$.

Se essa lógica traduzida na EC $95^{44}$ não for revertida, como os recursos destinados à saúde que já são insuficientes para atender à demanda, teríamos que construir câmaras de gás para os cidadãos que atingissem uma determinada idade em que o seu custo em saúde seria excessivo. Ademais, haveria de existir uma norma que bebês com menos de um quilo, salvo com cobertura privada, seriam deixados para morrer.

Não demoraria para que alguém propusesse a esterilização em massa das camadas mais pobres, chegando-se à solução final para a pobreza: a eliminação física dos pobres - e com eles a contenção do gasto em saúde com estas pessoas. Ou pior, como Diegues ${ }^{43}$ escreve a certa altura, os decadentes Homo sapiens seguiam espalhados em desordem pelo planeta, vagando pelas áreas mais pobres dos continentes, com famílias numerosas e sobrevivência cada vez mais curta.

Até que finalmente "por diversão e esporte, os Homo ricus passaram a caçar os Homo sapiens..." 43. Será essa nossa escolha? A reversão dessas medidas nos parece indispensável para qualquer projeto nacional que não incorpore soluções finais em suas estratégias. 


\section{Retomando o espírito de 1988}

O golpe de 2016 se deu em um contexto de uma crise de hegemonia no sentido gramsciano com uma separação das grandes massas de suas ideologias tradicionais e com o abandono de suas crenças anteriores ${ }^{45}$. Os representados da nossa democracia não mais se enxergam em seus representantes. Neste momento, a grande mídia assume a liderança da classe dominante e impõe sua pauta. Por outro lado, no campo progressista, após a virada para austeridade em 2015, a desconfiança dificulta a superação dos sectarismos e ampliação das alianças na classe dominada de forma a se articular para tentar assumir como nova classe dominante.

Neste quadro, $[. .$.$] a classe dominante perdeu$ seu consenso, isto é, não é 'dirigente', mas apenas 'dominante', exercendo apenas a força coercitiva, isto significa exatamente que as grandes massas se separam de suas ideologias tradicionais e não mais creem no que costumavam crer anteriormente, etc. A crise consiste precisamente no fato de que o velho está morrendo e o novo ainda não pode nascer. Nesse interregno, uma grande variedade de sintomas mórbidos aparece ${ }^{45(275-276)}$.

As crises de hegemonia podem apresentar diferentes desenlaces. A classe dominante mantém o seu status quo no curto prazo por meio da coerção, apostando que, em médio prazo, pode ocorrer uma recomposição de sua hegemonia. Já as classes dominadas precisam ampliar alianças, evitando o sectarismo, para poder subverter a ordem e assumir como nova classe dominante ${ }^{\mathbf{4 6}}$.

Os desdobramentos da ruptura democrática de 2016 isolaram cada vez mais os mecanismos de pressão popular sobre o Estado. As diversas tentativas de interdição não apenas da candidatura à presidência, mas do próprio direito de o ex-presidente Lula dar entrevistas colocam em xeque as possibilidades de disputa de hegemonia dentro do atual status quo.
De uma forma ou de outra, no quadro recessivo vigente no Brasil (com medidas econômicas que não procuram aliviar esta situação) e com o avanço das pautas de retrocessos em direitos como a contrarreforma trabalhista, a EC $n^{\circ} 95$, entre outras, podem ocorrer revoltas populares que fiquem fora de controle. A crise de hegemonia deve se acentuar; e convém recordar a analogia de Brecht entre o fascista e o burguês assustado, o crescimento de candidaturas ultraconservadoras.

Resta saber como enfrentaremos tal ameaça: com uma capitulação de algo como o que ocorreu com a Coligação da Esquerda Radical (Syriza), com uma articulação política nos termos da Geringonça em Portugal, ou se teremos enfrentamentos cada vez mais radicais na rua. Se, por acaso, isso resultar no fascismo, teremos pleno emprego sem objeções da burguesia e, claro, com todo seu pacote de maldades. Antes que seja tarde, abandonemos a responsabilidade fiscal em proveito da responsabilidade econômica e social.

Nesse sentido, retomamos mais uma vez Polanyi14(289):

A civilização do século XIX não foi destruída por ataques de bárbaros externos ou internos; sua vitalidade não foi solapada pelas devastações da Primeira Guerra Mundial, nem pela revolta de um proletariado socialista ou de uma classe média baixa fascista. Seu fracasso não foi conseqüência de alguma suposta lei de economia, como a taxa de lucros decrescentes, a do subconsumo ou a da superprodução. Ela se desintegrou como resultado de um conjunto de causas inteiramente diferentes: as medidas que a sociedade adotou para não ser aniquilada, por sua vez, pela ação do mercado auto-regulável. À parte as circunstâncias excepcionais que existiram na América do Norte, na época da fronteira aberta, o conflito entre o mercado e as exigências elementares de uma vida social organizada tanto proporcionou ao século a sua dinâmica como produziu as tensões e pressões típicas que, 
em última instância, destruíram aquela sociedade. As guerras externas apenas apressaram essa destruição.

Urge, portanto, dada a incapacidade de resposta do liberalismo, repaginado como neoliberalismo, aos problemas do nosso tempo, que se construa uma alternativa para que o fascismo não retorne. Esta não é uma tarefa apenas dos socialistas, dos comunistas ou dos sociais-democratas, mas dos seres humanos.

Estamos diante de mudança de época, uma crise de grande magnitude entre civilização ou barbárie. Há que se democratizar a revolução e revolucionar a democracia ${ }^{47}$. Não há saída sem retomada da dignidade da política, estratégica para a construção de uma sociedade fundada nos direitos sociais e humanos de cidadania, feminista, libertária, antirracista, compartilhada, diversa e radicalmente democrática. O momento histórico é de resgatar o espírito de 1988 !

\section{Colaboradores}

LRF Souto, GS Noronha e JC Noronha participaram da concepção, análise, redação do artigo e aprovação final do manuscrito. TR Pereira e AM Costa participaram da concepção, análise, revisão crítica relevante do conteúdo intelectual e aprovação final do manuscrito.

\section{Referências}

1. Piketty T. O capital no século XXI. Rio de janeiro: Intrínseca; 2014.

2. Oxfam. Terrenos da Desigualdade: Terra, agricultura e desigualdades no Brasil rural [internet]. Pinheiros: Oxfam; 2016 [acesso em $2016 \mathrm{dez}$ 10]. Disponível em: https://www.oxfam.org.br/sites/default/ files/arquivos/relatorio-terrenos_desigualdade-brasil.pdf.

3. McDonald C. How many Earths do we need? [internet]. [Sem local]: BBC News Magazine; 2015 [acesso em 2018 jul 10]. Disponível em: https://www.bbc. com/news/magazine-33133712.
4. United Nations. Sustainable Development Goals. Goal 12: Ensure sustainable consumption and production patterns [internet]. [Sem local]: Sustainable Development Goals; 2015. [acesso em 2017 fev 1]. Disponível em: http://www.un.org/sustainabledevelopment/sustainable-consumption-production/.

5. Worldwatch Institute. The State of Consumption Today [internet]. Washington, DC: Worldwatch Institute; c2018 [acesso em 2018 fev 3]. Disponível em: http://www.worldwatch.org/node/810.

6. Agamben G. Profanações. São Paulo: Boitempo; 2007. 
7. Luxemburgo R. A Crise da Social-Democracia: Folheto Junius [internet]. Zurique: [sem editora]; 1916 [acesso em 2012 ago 15]. Disponível em: http:// www.marxists.org/portugues/luxemburgo/1915/ junius/cap01.htm .

8. Cazes L. Filósofo István Mészáros analisa ascensão de novos partidos na Europa, como Syriza e Podemos [internet]. O Globo. 2016 fev 21 [acesso em 2016 ago 2]. Disponível em: http://oglobo.globo.com/cultura/livros/filosofo-istvan-meszaros-analisa-ascensao-de-novos-partidos-na-europa-como-syriza-podemos-15395541.

9. Marx K. O Capital. Crítica da Economia Política. Primeiro Livro - O Processo de Produção do Capital. Tomo 2. São Paulo: Nova Cultural; 1996.

10. Innes AM. What is Money? [internet]. The Banking Law Journal. maio 1913 [acesso em 2016 jul 1]. Disponível em: https://www.community-exchange. org/docs/what\%20is\%20money.htm.

11. Knapp GF. The State Theory of Money [internet]. Londres: Mcmillan \& Company; 1924. [acesso em 2017 set 20]. Disponível em: https://socialsciences. mcmaster.ca/econ/ugcm/3ll3/knapp/StateTheoryMoney.pdf.

12. Lerner AP. Functional finance and the federal debt. In: Selected economic writings. [internet]. New York: New York University Press; 1943 [acesso em 2018 jan 4]. Disponível em: http://cas2.umkc.edu/ economics/people/facultyPages/wray/courses/ Econ\%20601/readings/lerner\%20functional\%20 finance.pdf.

13. Kalecki M. Aspectos políticos do pleno emprego [internet]. Jornal GGN. 1942 [acesso em 2018 jan 4]. Disponível em: https://jornalggn.com.br/noticia/ aspectos-politicos-do-pleno-emprego-por-michal-kalecki.

14. Polanyi K. A Grande transformação: as origens da nossa época. Rio de Janeiro: Campus; 2000.

15. Braudel F. Civilização material, economia e capita- lismo: séculos XV-XVIII: o tempo do mundo. São Paulo: Martins Fontes; 2009.

16. Santos BS. A difícil democracia: reinventar as esquerdas. São Paulo: Boitempo; 2016.

17. Streeck W. Tempo comprado: a crise adiada do capitalismo democrático. Coimbra: Conjuntura Actual; 2013.

18. Streeck W. Como vai acabar o capitalismo? O epílogo de um sistema em desmantelo crônico. Rev Piauí [internet]. 2014 out [acesso em $2016 \mathrm{dez} 10$ ]; 97. Disponível em: http://piaui.folha.uol.com.br/materia/ como-vai-acabar-o-capitalismo/.

19. Tavares MC. A retomada da hegemonia norte-americana. Rev Econom Política. 1985 abr-jun; 5(2):5-15.

20. Marx K, Engels F. Manifesto Comunista. Rio de Janeiro: Garamond; 1998.

21. Fiori JL. Poder e Dinheiro. In: Seminário Poder e Dinheiro: uma economia política da globalização. Rio de Janeiro: UFRJ, Instituto de Economia; 2017 [acesso em 2018 jan 8]. Disponível em: https:// www.youtube.com/watch?v=KkVLCZihQ04.

22. Souza J. A radiografia do golpe: entenda como e por que você foi enganado. Rio de Janeiro: LeYa; 2016.

23. Lirio S. Jessé Souza: "A classe média é feita de imbecil pela elite" [internet]. Carta Capital. 2017 jun 23 [acesso em 2017 jun 25]. Disponível em: https://www.cartacapital.com.br/sociedade/jesse-souza-201ca-classe-media-e-feita-de-imbecil-pela-elite201d.

24. Santos WG. A democracia impedida: O Brasil no século XXI. Rio de Janeiro: FGV; 2017.

25. Sestelo JAF, Souza LEPF, Bahia L. Saúde suplementar no Brasil: abordagens sobre a articulação público/privada na assistência à saúde. Cad Saúde Pública [internet]. 2013 maio [acesso em 2018 jan 14]; 29(5):851-866. Disponível em: http://www. scielo.br/scielo.php?script=sci_arttext\&pid=S0102$-311 X 2013000500004 \& \operatorname{lng}=$ en. 
26. Organisation for Economic Cooperation and Development. OECD Health Statistics 2018 [internet]. [Sem local] OECD; c2018 [acesso em 2018 jan 5]. Disponível em: http://www.oecd.org/els/health-systems/health-data.htm.

27. Instituto Brasileiro de Geografia e Estatística. Conta-Satélite de Saúde Brasil 2010-2015. Rio de Janeiro: IBGE; 2017 [acesso em 2018 jan 10]. Disponível em: https://biblioteca.ibge.gov.br/visualizacao/livros/liv101437.pdf.

28. Brasil. Lei Complementar $n^{\circ} 141$, de 13 de janeiro de 2012. Regulamenta o 930 do art. 198 da Constituição Federal para dispor sobre os valores mínimos a serem aplicados anualmente pela União, Estados, Distrito Federal e Municípios em ações e serviços públicos de saúde; estabelece os critérios de rateio dos recursos de transferências para a saúde e as normas de fiscalização, avaliação e controle das despesas com saúde nas 3 (três) esferas de governo; revoga dispositivos das Leis nos 8.080, de 19 de setembro de 1990, e 8.689, de 27 de julho de 1993; e dá outras providências. Diário Oficial da União. 16 Jan 2012.

29. Rossi P, Dweck E. Impactos do Novo Regime Fiscal na saúde e educação. Cad. Saúde Pública [Internet]. 2016 [acesso em 2018 jan 14]; 32(12):1-5. Disponível em: http://www.scielo.br/pdf/csp/v32n12/16784464-csp-32-12-e00194316.pdf.

30. Dweck E, Oliveira ALM, Rossi P, coordenadores. Austeridade e retrocesso: impactos sociais da política fiscal no Brasil. São Paulo: Brasil Debate; Fundação Friedrich Ebert; 2018.

31. Vieira FS, Benevides RPS. O Direito à Saúde no Brasil em Tempos de Crise Econômica, Ajuste Fiscal e Reforma Implícita do Estado. Rev Estudos Pesquisas Am [internet]. 2016 [acesso em 2018 jan 8]; 10(3):32-59. Disponível em: http://periodicos.unb. br/index.php/repam/article/view/21860.

32. Gray J. The immortalization commission: science and the strange quest to cheat death. New York: Farrar; 2011.
33. Tavares GM. Uma Viagem à Índia: Melancolia contemporânea (um itinerário). São Paulo: Leya; 2010.

34. Robine JM. Life course, environmental change, and life span. Popul Dev Rev. 2003; 29(supl):229-238.

35. Fries JF. The compression of morbidity. Milbank Q. 2005 dez; 83(4):397-419.

36. Instituto Brasileiro de Geografia e Estatística. Projeção da população por sexo e idade: Brasil 20002060 [internet]. Rio de Janeiro: IBGE; 2013 [acesso em 2018 jan 12]. Disponível em: https://ww2.ibge. gov.br/home/presidencia/noticias/imprensa/ppts/ 00000014425608112013563329137649.pdf.

37. Noronha JC, Soares LT. A política de saúde no Brasil nos anos 90. Ciênc Saúde Colet. 2001; 6(2):445450.

38. Brasil Ministério da Saúde. Indicadores [internet]. Brasília, DF: MS; 2017 [acesso em 2018 jan 20]. Disponível em: http://portalms.saude.gov.br/repasses-financeiros/siops/indicadores .

39. Brasil. Agência Nacional de Saúde Suplementar. Dados e indicadores do setor [internet]. Rio de Janeiro: ANS; 2018 [acesso em 2018 jan 20]. Disponível em: http://www.ans.gov.br/perfil-do-setor/dados-e-indicadores-do-setor.

40. Noronha JC, Santos IS, Pereira T. Relações entre o SUS e a saúde suplementar: problemas e alternativas para o futuro do sistema universal. In: Santos NR, Amarante PDC, organizadores. Gestão pública e relação público privada na Saúde. Rio de Janeiro: Cebes; 2011. p. 152-179.

41. Brasil. Ministério da Fazenda. DGT PLOA 2018 [internet]. Brasília, DF: Ministério da Fazenda; 2018 [acesso em 2018 jan 20]. Disponível em: http://idg. receita.fazenda.gov.br/dados/receitadata/renuncia-fiscal/previsoes-ploa/arquivos-e-imagens/texto-dgt-ploa-2018-arquivo-final-para-publicacao. pdf/view.

42. Oxfam. Direitos humanos em tempos de austerida- 
de. Pinheiros: Oxfam; 2018 [acesso em 2018 jan 20]. Disponível em: https://www.oxfam.org.br/sites/default/files/arquivos/Fact_Sheet_2_Portugues_V_digital_2.pdf.

43. Diegues C. Seleção artificial. Rev Piauí [internet]. 2008 nov [acesso em 2018 jan 20]; 26. Disponível em: http://piaui.folha.uol.com.br/materia/selecao-artificial/.

44. Brasil. Emenda Constitucional $\mathrm{n}^{\circ} 95$, de 15 de dezembro de 2016. Altera o Ato das Disposições Constitucionais Transitórias, para instituir o Novo Regime Fiscal, e dá outras providências. Diário Oficial da União. 16 Dez 2016.
45. Gramsci A. Selections of the prison notebooks. New York: International Publishers; 1971.

46. Coutinho CN. Gramsci: Um estudo sobre seu pensamento político. Rio de Janeiro: Campus; 1989.

47. Canofre F. Boaventura de Sousa Santos: 'Estamos em uma transição da democracia para a ditadura?'. Sul 21. 2017 jun 2 [acesso em 2017 jun 25]. Disponível em: https://www.sul21.com.br/jornal/boaventura-de-sousa-santos-estamos-em-uma-transicao-da-democracia-para-ditadura/.

Recebido em 14/08/2018

Aprovado em 20/08/2018

Conflito de interesses: inexistente

Suporte financeiro: não houve 